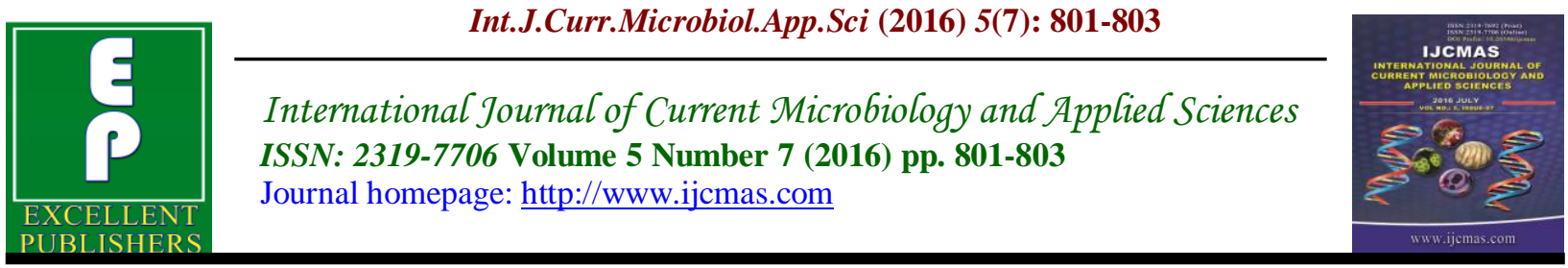

Case Study

http://dx.doi.org/10.20546/ijcmas.2016.507.092

\title{
A Case of Cerebral Toxoplasmosis as the Initial Presentation of HIV Infection
}

\author{
Varunika Vijayvergia*, Rameshwari Bithu, S.K. Singh and Rakesh Maheshwari \\ Department of Microbiology, SMS Medical college, India \\ *Corresponding author email id:
}

\begin{tabular}{|c|c|}
\hline & A B S T R A C T \\
\hline & \multirow{5}{*}{$\begin{array}{l}\text { Increasing incidences of the neurological complications are being encountered } \\
\text { nowadays with the increase in the incidence of HIV. These can be due to the direct } \\
\text { involvement of the CNS by the virus or due to the opportunistic infections. } \\
\text { Cerebral toxoplasmosis is a common opportunistic infection seen in HIV-infected } \\
\text { patients, but it has rarely been encountered before the diagnosis of HIV infection is } \\
\text { established. We report the case of a patient who presented with symptoms of } \\
\text { cerebral toxoplasmosis even before diagnosis of AIDS. Diagnosis was relied } \\
\text { essentially on the report of MRI scan, toxoplasma serology and the complete } \\
\text { recovery shown by the patient when put on the anti-toxoplasma therapy. It is to } \\
\text { highlight the fact that cerebral toxoplasmosis should always be considered in the } \\
\text { differential diagnosis of multiple ring enhancing neuroparenchymal lesions in } \\
\text { young individuals presenting with neurological symptoms. As it is a treatable entity } \\
\text { so the early recognition is the key which can lead to the complete and timely cure } \\
\text { of the patient. }\end{array}$} \\
\hline & \\
\hline $\begin{array}{l}\text { Cerebral } \\
\text { Toxoplasmosis, } \\
\text { HIV Infection, } \\
\text { MRI scan, } \\
\text { toxoplasma } \\
\text { serology. }\end{array}$ & \\
\hline Article Info & \\
\hline $\begin{array}{l}\text { Accepted: } \\
\text { 25 June } 2016 \\
\text { Available Online: } \\
\text { 10 July } 2016\end{array}$ & \\
\hline
\end{tabular}

\section{Introduction}

Toxoplasma gondii is an obligate intracellular parasite infecting both animals and humans (Blader et al., 2009). Prevalence rate of Toxoplasma infection among HIV (Human immune deficiency virus) positive individuals vary widely across the world, ranging from $3 \%$ to $97 \%$ (Nissapatorn et al., 2009). Cats are the definitive hosts. Transmission occurs either due to the ingestion of the oocysts (excreted in the cats feaces) from contaminated soil, food and water or from undercooked meat (Dubey et al., 1996). The major clinical features of cerebral toxoplasmosis are headache, fever, altered sensorium, seizures and focal neurological deficits. T.gondii infection remains asymptomatic in immunecompetent persons but in the immunocompromised individuals, as the CD4+ $\mathrm{T}$ cell lymphocyte count decreases below 200 cells $/ \mu 1$, reactivation of the latent $T$.gondii infection occurs resulting in life threatening complications such as toxoplasmic encephalitis (Kodym et al., 2015).

It is known to be preceded by many other AIDS (Acquired immunodeficiency syndrome) defining illnesses and is rarely seen as the first presentation. But here, we present a case of a HIV positive young male, totally unaware about his HIV status, which 
only came in to light when he developed the sudden onset of toxoplasmic encephalitis. We are presenting this case to highlight the fact that cerebral toxoplasmosis should also be considered in the differential diagnosis of the multiple neuroparenchymal lesions in young individuals who present with neurological deficits and also a high index of suspicion should be kept for the HIV associated cerebral toxoplasmosis.

\section{Case Report}

A 27 year male, chronic smoker \& alcoholic presented to the emergency department with the chief complaint of sudden onset right sided hemiplegia and aphasia along with altered sensorium. He denied any major illness or hospitalization in the past, but had some non specific constitutinal symptoms since one year. On examination he was slow with altered sensorium and only kerning's sign was positive. Rest of the neurological and systemic examinations were unremarkable. His basic lab investigations were within normal range except for the low lymphocyte count (07) in DLC. On gross examination CSF was clear and normal on microscopy. Sugar and protein level were also within normal limits. MRI brain revealed multiple cystic ring enhancing lesions of variable sizes seen diffusely scattered in bilateral cerebellar and cerebral hemispheres especially in periventricular locations, basal ganglia, thalami and brainstem.

Most of them were having restricted diffusion, associated with marked perilesional vasogenic oedema suggestive of inflammatory granulomas. The largest lesion in the left frontal lobe was showing target lesion and heterogenous involvement. MRI findings were suggestive of toxoplasmosis. So his toxoplasma serology was done by chemiluminesans (Cobas e 411, Roche.
Hitachi), which was positive for IgG. His CSF was also positive for antitoxoplasma IgG but negative for IgM. Subsequently, his HIV test was done which was positive for HIV-1 infection and CD4 count was found to be 69 cells/ $\mu 1$ (FACS CALIBUR, BD)

Patient was given antitoxoplasma therapy (sulfadoxime/ pyramithimine and clotrimoxazole) along with steroids and glycerol. Simultaneously he was also put on HAART. He responded well to the treatment with good neurological recovery by $4^{\text {th }}$ day and was discharged in two weeks after proper counselling.

\section{Results and Discussion}

The origin of T. gondii infection in this HIV infected male with a rural background is uncertain. It is likely that instead of a newly acquired toxoplasmic infection, the patient might have a previous latent infection that was reactivated following the low CD4 count induced by the HIV infection. According to CDC guidelines on toxoplasmosis, presence of elevated $\mathrm{IgG}$ alone suggest infection of more than six months duration. Elevated $\operatorname{IgM}$ is not so specific. It suggests acute infection only when followed by subsequent increase in IgG. Establishing a definitive diagnosis of cerebral toxoplasmosis in a resource limited setting is generally based on the radiographic features and toxoplasmic serology. It is often correlated with the adequate response to the therapeutic trial. The definitive diagnostic procedures such as brain biopsy (Yoganathan et al., 2009) and PCR (Mathews et al., 1995) are considered only in patients with inadequate response or negative toxoplasma serology.

Cerebral toxoplasmosis and primary cerebral lymphoma are the most common causes of ring enhancing lesions of central nervous 
system in patients with AIDS. Other conditions that can mimic are tuberculomas, gliomas, metastases and abscesses (Garg et al., 2010) As suggested other studies, in our study also cerebral toxoplasmosis occurred after the CD4+T lymphocyte count fell below 200 (Kodym et al., 2015) ie; 69 cells/ $\mu 1$.

Considering this fact, toxoplasma chemoprophylaxis should be considered in all HIV positive individuals to prevent occurrence of encephalitis. Education about prevention of toxoplasma infection by following proper hygienic practices such as hand washing after gardening/farming (to minimize the contamination with oocyst) should be included in the routine counseling protocol to create awareness about the disease.

\section{References}

Blader, I.J., Saeij, J.P. 2009. Communication between Toxoplasma gondii and its host: impact on parasite growth, development, immune evasion, and virulence. APMIS : acta pathologica, microbiologica, et immunologica Scandinavica, 117(5-6): 458-76.

Dubey, J.P. 1996. Toxoplasma Gondii. In: Baron S, editor. Medical Microbiology. 4th edition. Galveston (TX): University of Texas Medical Branch at Galveston, Chapter 84.

Garg, R.K., Sinha, M.K. 2010. Multiple ring-enhancing lesions of the brain. $J$. Postgrad. Med., 56: 307-16.

Kodym, P., Malý, M., Beran, O., Jilich, D., Rozsypal, H., Machala, L., et al. 2015. Incidence, immunological and clinical characteristics of reactivation of latent Toxoplasma gondii infection in HIVinfected patients. Epidemiol. Infect., 143(3): 600-607.

Mathews, C., Barba, D., Fullerton, S.C. 1995. Early biopsy versus empiric treatment with delayed biopsy of nonresponders in suspected HIVassociated cerebral toxoplasmosis: a decisioanalysis. AIDS, 9: 1243-50.

Nissapatorn, V. 2009. Review toxoplasmosis in HIV/AIDS: a living legacy. Southeast Asian J. Trop. Med. Public Health, 40(6): 1158-1178.

Yoganathan, K. 2009. A "brain tumor" in an intravenous drug abuser. International J. General Med., 2: 73-75.

\section{How to cite this article:}

Varunika Vijayvergia, Rameshwari Bithu, S.K. Singh and Rakesh Maheshwari. 2016. A Case of Cerebral Toxoplasmosis as the Initial Presentation of HIV Infection. Int.J.Curr.Microbiol.App.Sci. 5(7): 801-803. doi: http://dx.doi.org/10.20546/ijcmas.2016.507.092 